\title{
DEVELOPMENT AND VALIDATION OF HPTLC METHOD FOR DETERMINATION APIXABAN IN BULK AND TABLETS
}

\author{
HEMANT K. JAIN*, VISHAL K. NIKAM
}

Department of Quality Assurance Techniques, Sinhgad College of Pharmacy, Vadgaon (Bk.), Pune 411041, Maharashtra, India Email: hemantkjain2001@yahoo.co.in

Received: 16 May 2017, Revised and Accepted: 22 Aug 2017

\section{ABSTRACT}

Objective: To develop a simple and sensitive, high-performance thin layer chromatographic (HPTLC) method for the quantitative estimation of apixaban in bulk and tablets.

Methods: Sample of apixaban was applied on silica gel 60 F254 TLC plates under pure nitrogen stream by linomat TLC applicator. Separation was carried out by using toluene, methanol and diethylamine as a mobile phase in a ratio of 16:3:1 v/v/v. Developed TLC plates were scanned by camag TLC scanner and detection was carried out at $288 \mathrm{~nm}$.

Results: Rf value of apixaban was found to be 0.4 . The linearity was found from 50 to $350 \mathrm{ng} / \mathrm{spot}$. The mean percentage recovery was found to be 85.66with \% RSD of 0.79 .

Conclusion: The present study represents first HPTLC method that deals with the estimation of apixaban. Validation results indicated that the developed method is simple, rapid, accurate, specific, sensitive and precise. The developed method was validated as per ICH Q2 (R1) guideline by studying various validation parameters like accuracy, precision, specificity, assay, LOD and LOQ. It can be concluded that the method can be used in routine analysis of apixaban in tablet dosage form.

Keywords: Apixaban, Toluene, Methanol, Diethylamine, HPTLC

(C) 2017 The Authors. Published by Innovare Academic Sciences Pvt Ltd. This is an open access article under the CC BY license (http://creativecommons.org/licenses/by/4.0/) DOI: http://dx.doi.org/10.22159/ijap.2017v9i5.20028

\section{INTRODUCTION}

Apixaban is chemically 1-(4-methoxyphenyl)-7-oxo-6-[4-(2-oxo piperidin-1-yl) phenyl]-4,5,6,7-tetrahydro-1H-pyrazolo $[3,4-$ c]pyridine-3-carboxamide [fig. 1]. It is a new generation of oral anticoagulant drug that selectively inhibits coagulation factor Xa. [1]. It is used in thromboprophylaxis in patients following total knee replacement surgery with a desired efficacy and safety profile [2]. FDA approved apixaban (eliquis, bristol-myers squibb/pfizer) on december 28, 2012 for the prevention of stroke and systemic embolism in patients with nonvalvular atrial fibrillation (AF) [3]. Apixaban is not an official drug in any Pharmacopoeia. Literature survey reveals that some methods have been reported for their determination of apixaban by HPLC [4-6] and hyphenated techniques such as UPLC-MS/MS [7-8], LCMS [9-10], GCMS [11], either alone or in combination. Most of the reported methods are based on hyphenated techniques and overall cost of the analysis using these techniques is more as compared to high-performance thin layer chromatography [12-15]. There is no HPTLC method available yet for estimation of apixaban in tablets. This paper presents development and validation of a simple, accurate and precise HPTLC method for estimation of apixaban in bulk and tablets.

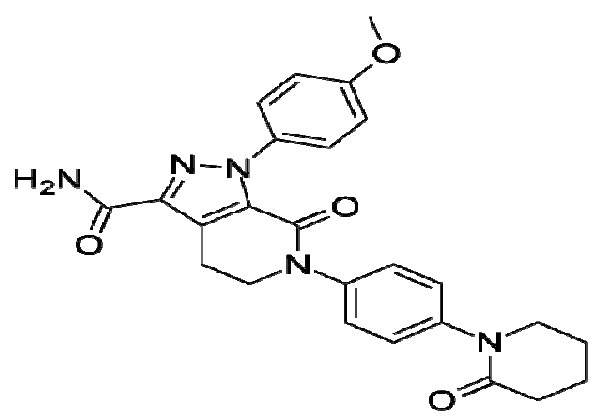

Fig. 1: Chemical structure of apixaban

\section{MATERIALS AND METHODS}

\section{Materials}

Apixaban standard was procured from Wockhardt research centre, Chikalthana, India as a gift sample. Commercially available tablets (eliquis ${ }^{\circledR} 5$ mg of apixaban) were procured from local the market. Precoated silica gel $60 \mathrm{f} 254$ TLC (e-merck, Germany) plates $(10 \times 10 \mathrm{~cm})$ were used as stationary phase and a mixture of toluene, methanol and diethylamine was used as mobile phase. HPLC grades of all solvents used for this study were obtained from merck pvt. ltd, Mumbai.

\section{Instrument}

The method was performed on camag (Switzerland) twin trough chamber, visualizer with automatic injection facility ATS 4 and TLC scanner 4.

\section{Preparation of working solution}

An accurately weighed $5 \mathrm{mg}$ of apixaban was transferred into a 20 $\mathrm{ml}$ test-tube. Five ml of a mixture of dimethyl formamide: methanol (1:4) was added to it and solution was sonicated for $15 \mathrm{~min}$. This solution $(1 \mathrm{mg} / \mathrm{ml})$ was further diluted by dimethyl formamide: methanol (1:4) to obtain $100 \mu \mathrm{g} / \mathrm{ml}$.

\section{Selection of detection wavelength}

$5 \mu \mathrm{l}$ of apixaban $(1000 \mu \mathrm{g} / \mathrm{ml})$ was applied using automatic injection facility ATS 4 on precoated silica gel $60 \mathrm{f}_{254}$ TLC plates and scanned by camag TLC scanner 4 .

\section{Analytical method validation}

The developed chromatographic method was validated for system suitability, linearity, range, specificity, accuracy, precision, assay, LOD-LOQ and robustness parameters, as per ICH guidelines [16].

\section{Linearity and range}

Working standard solutions were injected under the optimized chromatographic conditions and peak areas were calculated at $288 \mathrm{~nm}$. 
The calibration curve was plotted between areas against corresponding concentrations of the drug. Linear regression data for calibration curve was shown in fig. 4. The range of solution has been decided according to a correlation coefficient of the regression equation.

\section{Precision}

Repeatability and intermediate precision studies were carried out with 10 replicates of standard solutions of apixaban (200 ng/spot). Area of each spot was measured at $288 \mathrm{~nm}$ and relative standard deviation (\%RSD) was calculated. Inter-day precision studies were performed using same concentrations on three different days. The results of the precision study have been tabulated in (table 3)

\section{Accuracy}

The accuracy of the method was carried out by adding the known amount of drug corresponding to three given concentration levels $(80 \%, 100 \%, 120 \%)$.

Percent recovery of apixaban was determined at three different level $80 \%, 100 \%$, and $120 \%$ of the target concentration in triplicate. The results of accuracy study are shown in table 4 .

\section{Limit of detection (LOD) and limit of quantitation (LOQ)}

Five sets of 50-350 ng/spot were prepared and the corresponding areas of these sets were measured. Calibration curves were plotted for each set. The standard deviation of the y-intercept and average slope of the calibration curve was used to calculate LOD and LOQ using following formulae.

$$
L O D=\frac{3.3 \mathrm{MD}}{\mathrm{s}} L O Q=\frac{10 \times \mathrm{sL}}{\mathrm{s}}
$$

Where SD is the standard deviation of y-intercepts of the calibration curves; $\mathrm{S}$ is a mean slope of five calibration curves. Results for determination of LOD and LOQ studies are shown in table 5.

\section{Specificity}

The specificity of the method was determined by analyzing individual spot of standard drug, sample, diluent and mobile phase.

\section{Assay of tablets}

Twenty tablets were weighed and average weight was calculated. These tablets were crushed and powdered in a glass mortar. The tablet powder equivalent to the average weight of apixaban was accurately weighed, transferred to a $50 \mathrm{ml}$ of volumetric flask and diluted up to mark with dimethyl formamide: methanol (1:4). The solution was filtered through whatman filter paper No. 41 and the first $5 \mathrm{ml}$ of filtrate were discarded. This procedure was repeated in triplicate. The results of the assay of tablets are shown in table 2 .

\section{RESULTS AND DISCUSSION}

\section{Optimization of chromatographic conditions}

Following chromatographic conditions were chosen for analysis on the basis of trial and error, using different solvent systems. Precoated silica gel $60 \mathrm{f}_{254}$ TLC plates were prewashed with methanol and activated at $110{ }^{\circ} \mathrm{C}$ for $10 \mathrm{~min}$ prior to application. The standard samples of apixaban were spotted on precoated TLC plates in the form of bands of length $4 \mathrm{~mm}$ using $100 \mu \mathrm{l}$ sample syringe with a linomat-5 applicator. The chromatographic development was carried using toluene: methanol: diethylamine (16: $3: 1 \mathrm{v} / \mathrm{v} / \mathrm{v}$ ) as mobile phase with chamber saturation time of 20 min and the migration distance of $70 \mathrm{~mm}$. Densitometric scanning was performed using camag TLC scanners operated by win CATS Software (version 2.3.316286.1) and detection wavelength was found to be $288 \mathrm{~nm}$. (fig. 2).

\section{Assay of marketed formulation}

The value of mean \% drug was found to be $108.02 \%$ (table 2).

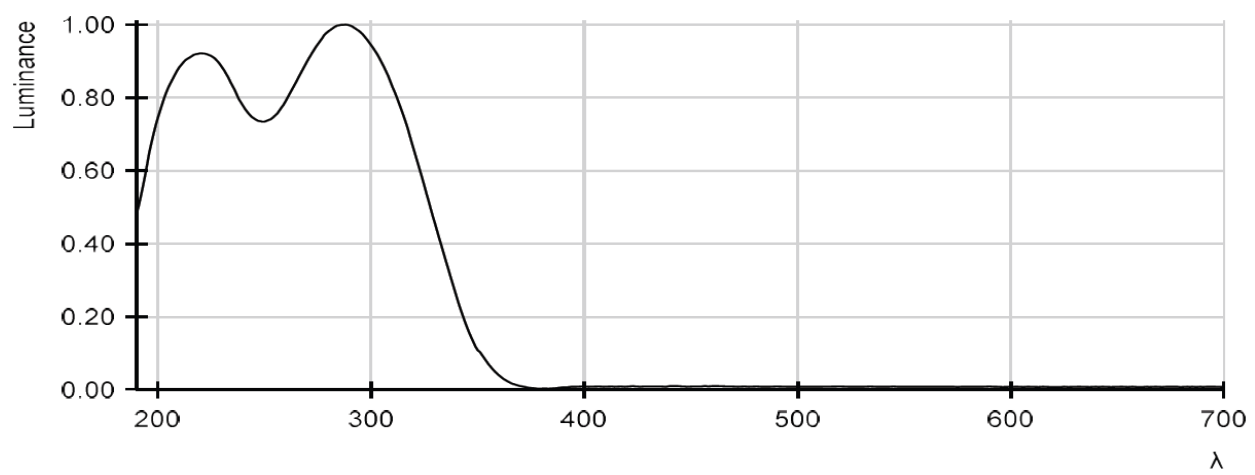

Fig. 2: Spectrum scan developed plate

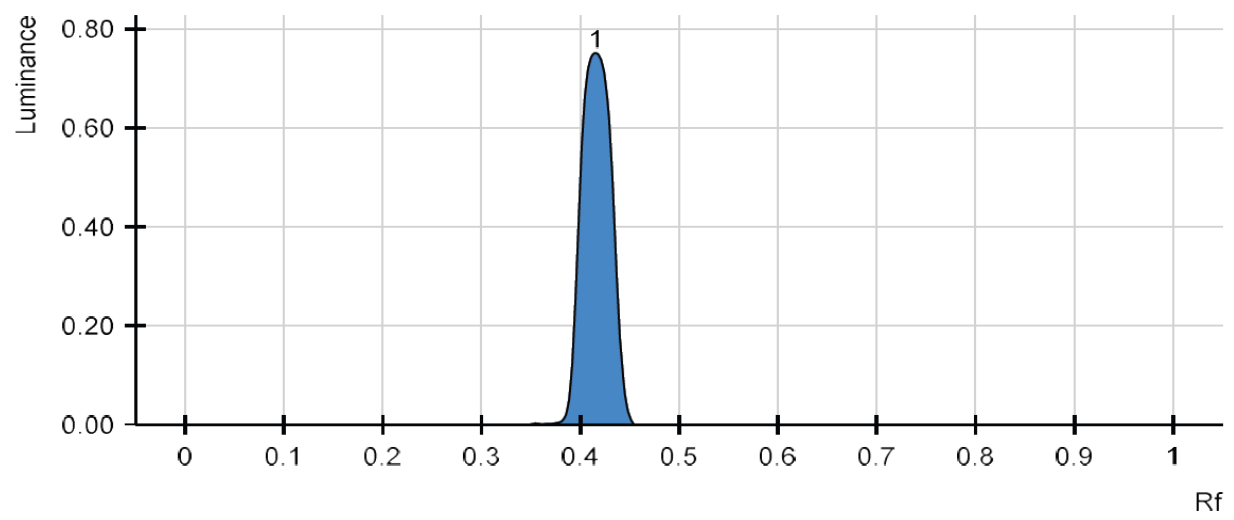

Fig. 3: UV spectrum of apixaban at $288 \mathrm{~nm}$ 
Table 1: Optimized chromatographic conditions

\begin{tabular}{ll}
\hline Parameters & Details \\
\hline Mobile phase & Toluene: methanol: diethylamine $(16: 3: 1) \mathrm{v} / \mathrm{v} / \mathrm{v}$ \\
Plates & TLC Al plates $(10 \mathrm{x} 10 \mathrm{~cm})$ Si $60 \mathrm{~F}_{254}$ \\
$\mathrm{R}_{\mathrm{f}}$ value & 0.4 \\
Application type & Band \\
Detection & UV at $288 \mathrm{~nm}$ \\
Saturation time & $10 \mathrm{~min}$ \\
Solvent front position & $70.0 \mathrm{~mm}$ \\
Application & Position Y: $8.0 \mathrm{~mm}$, length: $8.0 \mathrm{~mm}, \mathrm{width:} 0.0 \mathrm{~mm}$ \\
Diluent & Toluene: methanol: diethylamine $(16: 3: 1) \mathrm{v} / \mathrm{v} / \mathrm{v}$ \\
\hline
\end{tabular}

Table 2: Assay of marketed formulation of apixaban

\begin{tabular}{lll}
\hline S. No & Sample solution concentration (ng/spot) & Actual Concentration found (ng/spot) \\
\hline 1 & 150 & 160.5 \\
2 & 150 & 162.1 \\
3 & 150 & 164.1 \\
\hline
\end{tabular}

*The value is represented as a mean \pm SD of 3 observations.

\section{Linearity and range}

The appropriate volume of an aliquot from standard apixaban stock solution was filled in the syringe under nitrogen stream by an automatic sample applicator. The linearity was determined by using working standard solutions between 50-350 ng/spot. The spectrums of these solutions were recorded at wavelength $288 \mathrm{~nm}$. Calibration curve of peak area $v / s$ concentration was plotted after suitable calculation and simple linear regression was performed. The range of solution has been decided according to statistical parameters of generated equation. Regression equation and correlation coefficient were obtained $\left(R^{2}=0.9965\right)$ shown in the fig. 4 .

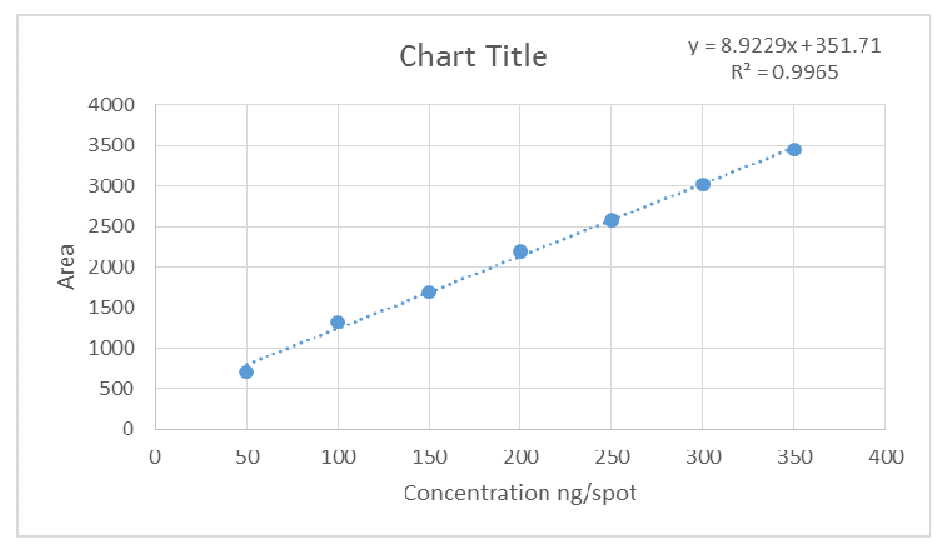

Fig. 4: Calibration curve of apixaban

\section{Precision}

For repeatability studies, the spot was repeated ten times without changing the syringe and position of plates. Mean area, standard deviation, and coefficient of variance were calculated. Inter-day precision was determined by analyzing $200 \mathrm{ng} /$ spot concentration of apixaban individually for ten times. The values of \%RSD of repeatability and intermediate precision studies were found within the acceptable limit (table 3 ). Therefore, the method is precise.

\section{Accuracy}

Accuracy study was performed at a spiking level of 80, 100 and $120 \%$ of target concentration. The values of percent recovery of the developed method (table 4) were found in acceptance criteria.
Results of accuracy studies of the method were found satisfactory as the average mean recovery $\pm \mathrm{SD}$ was $85.66 \pm 0.79$. Therefore, this method is accurate.

\section{Limit of detection (LOD) and limit of quantitation (LOQ)}

The values of LOD and LOQ have been found to be $86 \mathrm{ng} / \mathrm{spot}$ and $262 \mathrm{ng} / \mathrm{spot}$, respectively.

\section{Specificity}

Track of standard apixaban API, sample, mobile phase, and diluent are obtained by camag TLC scanner (fig. 5 to 8) for specificity test. There is no interference has been observed between the peaks of drug, diluent and mobile phase. Therefore, the developed method was found to be specific.

Table 3: Repeatability and intermediate precision

\begin{tabular}{lll}
\hline Precision & Amount of drug (ng/spot) & Mean area \pm SD* \\
\hline Repeatability $(\mathrm{n}=10)$ & 200 & $4804.4 \pm 66.89$ \\
Inter-day $(\mathrm{n}=10)$ & 200 & 1.389 \\
\hline
\end{tabular}

*The value is represented as a mean \pm SD of 10 determinations; \% RSD* relative standard deviation 
Jain et al.

Table 4: Accuracy study of apixaban

\begin{tabular}{lllll}
\hline Levels & Amount taken (ng) & Amount found (ng/spot) & \% recovery & Mean \% recovery \pm \%SD* \\
\hline \multirow{2}{*}{$80 \%$} & \multirow{2}{*}{160} & 155.34 & 86.30 & $87.11 \pm 0.86$ \\
& & 158.43 & 88.01 & 87.02 \\
$100 \%$ & \multirow{2}{*}{200} & 156.64 & 85.71 & $86.54 \pm 0.90$ \\
& & 171.43 & 87.49 & 86.43 \\
$120 \%$ & 240 & 174.98 & 84.52 & $83.31 \pm 1.06$ \\
\end{tabular}

*The value is represented as a mean $\pm \mathrm{SD}$ of 3 observations.

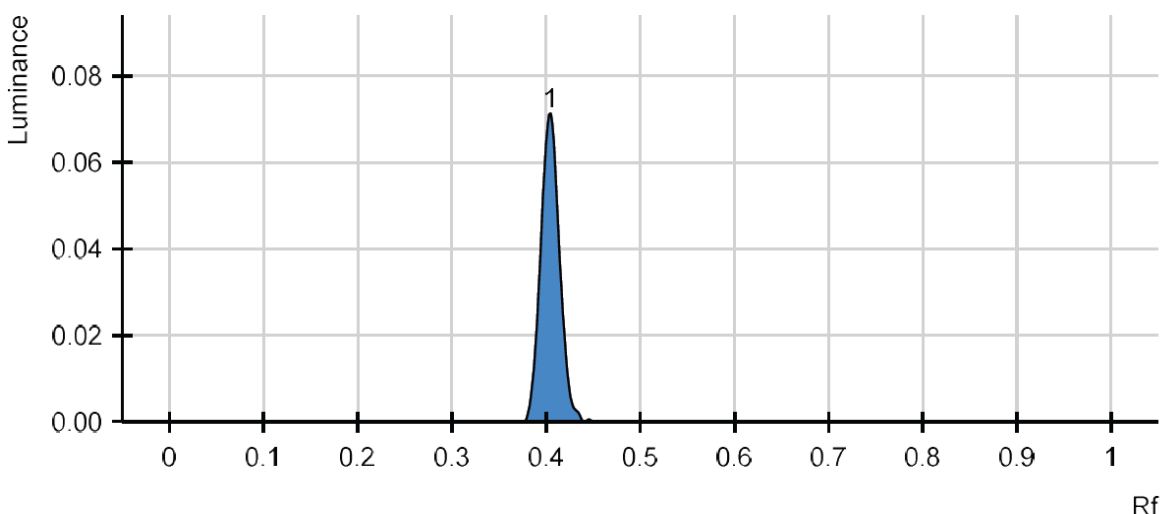

Fig. 5: Track of standard apixaban API

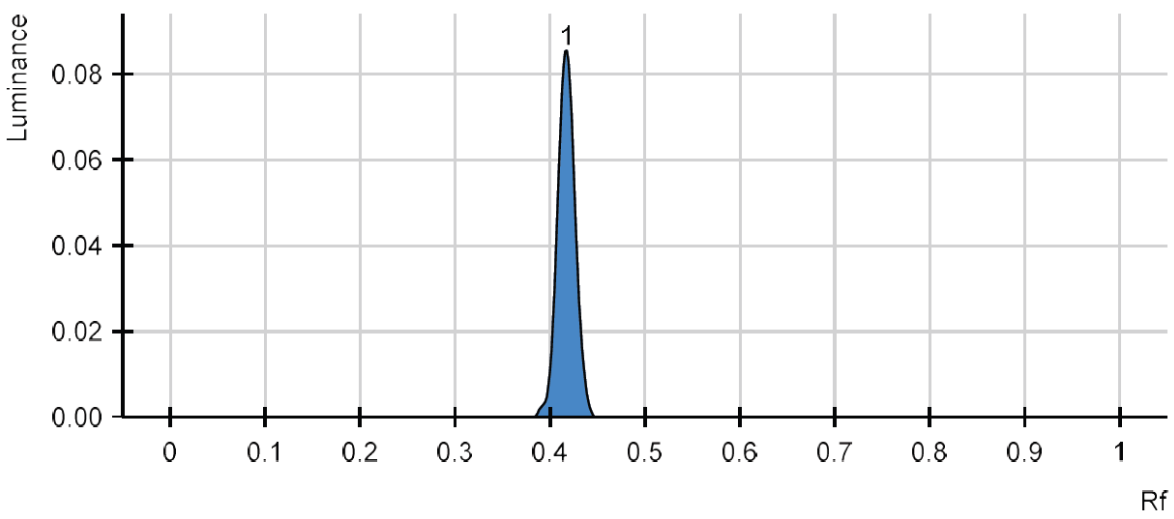

Fig. 6: Track of apixaban sample

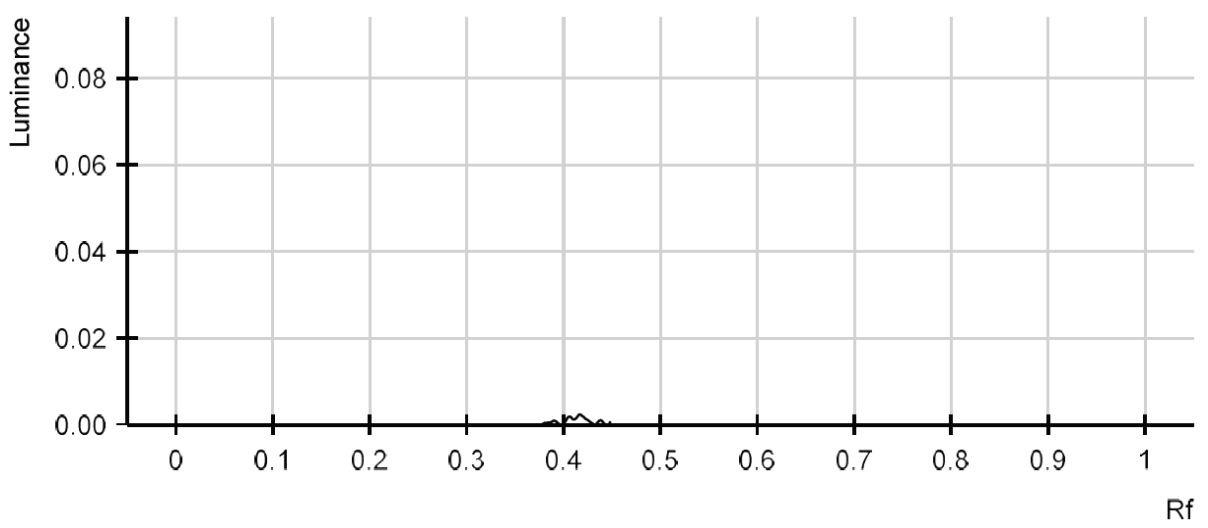

Fig. 7: Track of mobile phase [toluene: methanol: diethylamine (16: 3: $1 \mathrm{v} / \mathrm{v} / \mathrm{v})$ ] 


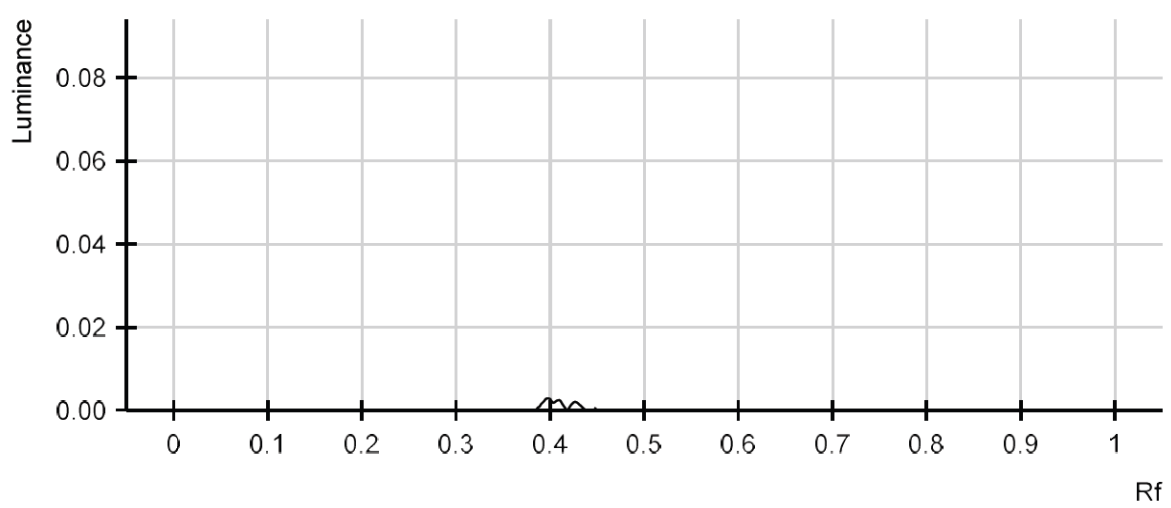

Fig. 8: Track of diluent [dimethyl formamide: methanol (1:4 v/v)]

\section{CONCLUSION}

It can be concluded from the results that the proposed method is accurate, precise and consistent the determination of apixaban in tablet dosage form. This method was validated as per ICH guideline Q2 (R1). Results suggest that this method can be used for routine estimation of apixaban in bulk and pharmaceutical dosage forms.

\section{ACKNOWLEDGEMENT}

The authors are grateful to the Wockhardt research centre, Chickhalthana, MIDC, Aurangabad, India for providing API of apixaban as a gift sample. Authors also thanks to Anchrom Enterprises Pvt. Ltd. Mumbai, India, and Principal, Sinhgad college of pharmacy, Pune, SPPU, India for providing necessary facilities to complete this project.

\section{CONFLICT OF INTERESTS}

Declared none

\section{REFERENCES}

1. Pinto DJ. Discovery of 1-(4-methoxyphenyl)-7-oxo-6-(4-(2-oxo piperidine-1-yl) phenyl)-4, 5, 6, 7-tetrahydro-1 H-pyrazolo [3, 4-c] pyridine-3-carboxamide (Apixaban, BMS-562247), a highly potent, selective, efficacious and orally bioavailable inhibitor of blood coagulation factor Xa. J Med Chem 2007; 50:5339-56

2. Lassen MR. The efficacy and safety of apixaban, an oral, direct factor Xa inhibitor, as thromboprophylaxis in patients following total knee replacement. J Thromb Haemostasis 2007;5:2368-75.

3. FDA approves apixaban for stroke prevention in nonvalvular AF-Medscape; 2012.

4. Landge SB. Development and validation of stability indicating RP-HPLC method on core shell column for determination of degradation and process related impurities of apixaban-an anticoagulant drug. Am J Anal Chem 2015;6:539-50.

5. Prabhune SS, Jaguste RS, Kondalkar PL, Pradhan NS. Stabilityindicating high-performance liquid chromatographic determination of apixaban in presence of degradation products. Sci Pharm 2014;82:777-85.

6. Katta R, Nagaraju C, Ramashrinivas, Rao GN. Two novel validated RP-HPLC and UV spectrophotometric methods for estimation of apixaban in bulk and pharmaceutical dosage forms. Am J PharmTech Res 2015;5:4.

7. Zhang W, Lou D, Zhang D, Zhang Y, Huang H. Determination of rivaroxaban, apixaban and edoxaban in rat plasma by UPLCMS/MS method. J Thromb Thrombolysis 2016;42:205-11.

8. Schmitz E. Determination of dabigatran, rivaroxaban and apixaban by ultra-performance liquid chromatography-tandem mass spectrometry (UPLC-MS/MS) and coagulation assays for therapy monitoring of novel direct oral anticoagulants. J Thromb Haemostasis 2014;12:1636-46.

9. Delavenne X, Mismetti P, Basset T. Rapid determination of apixaban concentration in human plasma by liquid chromatography/tandem mass spectrometry: application to pharmacokinetic study. J Pharm Biomed Anal 2013;78-79:150-3.

10. Tilea I. Determination of apixaban levels in human plasma by a high-throughput liquid chromatographic tandem mass Spectrometry assay. Rev Romana Med Lab 2015;23:2-25.

11. Tantawy MA, El-Ragehy NA, Hassan NY, Abdelkawy M. Stability-indicating spectrophotometric methods for determination of the anticoagulant drug apixaban in the presence of its hydrolytic degradation product. Spectrochim Acta Mol Biomol Spectrosc 2016;159:13-20.

12. Vaghela D, Patel P. High-performance thin layer chromatographic method with densitometry analysis for determination of rivaroxaban from its tablet dosage form. Int J Pharm Pharm Sci 2014;6:383-6.

13. Rathinam S, Lakshmi KS. High-performance thin layer chromatographic method for the simultaneous estimation of camylofin dihydrochloride and mefenemic acid in a pharmaceutical tablet. Int J Pharm Pharm Sci 2014;6:585-9.

14. Patel DJ, Desai SD, Savaliya RP, Gohil DY. Simultaneous HPTLC determination of lopinavir and ritonavir in combined dosage form. Asian J Pharm Clin Res 2011;4:59-61.

15. Aher A, Jain HK. Development and validation of HPTLC method for determination of gliclazide in API and pharmaceutical dosage form. World J Pharmacy Pharm Sci 2014;4:1485-93.

16. ICH Harmonized-Tripartite Guidelines. Validation of Analytical Procedure: Text and Methodology. November Q2 (R1); 2005.

\section{How to cite this article}

- Hemant K Jain, Vishal K Nikam. Development and validation of HPTLC method for determination apixaban in bulk and tablets. Int ] Appl Pharm 2017;9(5):78-82. 